\title{
Providing Public Value through Data Sharing: Understanding Critical Factors of Food Traceability for Local Farms and Institutional Buyers
}

\author{
Mila Gascó \\ University at Albany, SUNY \\ mgasco@ctg.albany.edu
}

\author{
Wenhui Feng \\ University at Albany, SUNY \\ wfeng@albany.edu
}

\author{
J. Ramon Gil-Garcia \\ University at Albany, SUNY \\ jgil-garcia@ctg.albany.edu
}

\begin{abstract}
Many of the datasets that could contribute to solutions for current public problems are proprietary and reside outside of government agencies. Accelerating data sharing and collaboration between those who hold valuable data and those able to deliver solutions is key to generating public value from private data. There is still a limited body of literature, however, that addresses data sharing and collaboration between private and public organizations. Using a case study of food traceability from local farms to institutions, this paper contributes to this emerging field by identifying challenges and incentives in data sharing among different types of organizations. In particular, our goal is to study how small farms and institutional buyers can be incentivized to share their data in a way that contributes to food safety, public health, and other societal goals. Our findings demonstrate that initiatives which can show the benefits of having a whole-chain food traceability system, have clear policies and regulations, and opportunities for participation in training activities are key incentives.
\end{abstract}

\section{Introduction}

Information has become increasingly important in modern life. In the last decade, governments around the world have created open data repositories, primarily to make government data sets available to the public. Many of the datasets that were previously only maintained within a government agency are now freely available online in easily accessible formats.

Yet, many of the datasets that could contribute to the development of solutions for public problems are proprietary [1]. Many public and most private organizations maintain valuable data, which is

\footnotetext{
${ }^{1}$ Although the public-private distinction is still a significant area of organizational research that needs further analysis, as Rainey and Bozeman [39] and Perry and Rainey [40] suggest, a simple definition describes public organizations as those owned and funded by
}

sometimes also well-organized ${ }^{1}$. Often, this information is of interest to government agencies and to the public. For example, coffee consumers may want to have access to information about their coffee, including where it comes from and how it was handled.

Accelerating data sharing and collaboration among those who hold valuable data and those able to deliver solutions is key to reaping the public value from all kinds of data [1][2]. Further, information sharing of data with citizens and consumers, often addressed as smart disclosure in both the United States and the United Kingdom [3], may help the public make better informed choices regarding their health, food habits, and shopping practices, to name just a few examples [4].

Jarman and Luna-Reyes [2] argue that there are four main benefits to disclosing data owned by private companies and/or public and non-profit organizations: 1) disclosure may allow individual members of the public better access to, and control over, their own data, 2 ) individuals may act on this new information, making their actions more efficient or valuable for themselves, the public, or both, 3) better aggregate public awareness and scrutiny of what governments, businesses, and other organizations do may lead to demands for better behavior, and 4) disclosure may result in increased opportunities for innovation and economic growth based on the disclosed data.

Different policy domains can benefit from smart disclosure. Susha, Jannsen, and Verhulst [1] refer to the Data Collaboratives initiative, led by the GovLab. Under this initiative, organizers have set up databases for projects with shared data to deliver greater public value. Such database includes cases in five different domains: health, economic development, education, environment, and infrastructure. In addition, Sayogo and Pardo [4] analyze the Green Button project in the energy and utilities industry, identifying what motivates participants to share data. Further, I-Choose, a research project that was funded by the National Science

government, while private organizations as those owned and funded through sales or private donations [41]. Organizations that overlap represent mixed or hybrid types. 
Foundation to better understand the requirements and impacts of information disclosure on firm and consumer behavior, also shows that food safety is another policy domain where private data disclosure and data collaborations between private and public actors have the potential to create public benefits [2].

Despite the initiatives and projects described here, smart disclosure is an emergent topic in the field of information and data sharing; accordingly, there is scant literature that addresses data sharing and collaboration between private and public organizations [1]. Our paper aims to contribute to this area of research by analyzing the benefits and challenges of a whole-chain food traceability system, from local and small farms in New York State to institutional buyers (such as universities and schools). The idea behind the project is that food safety policies require some level of traceability, revealing information about the origin, location, and life history of a product across the supply-chain. In addition to providing more and better data to support the development of improved food safety policies, a traceability system enables quicker identification of the sources of food borne illnesses and enables more small farms to sell their products to mainstream markets through wholesalers and retailers who can add them to their chain-of-custody, track products from source to customer, and benefit from premium market prices of "locally grown" products.

Our study is motivated by two research questions: 1) what are the main challenges different types of actors (small farms and institutional buyers, but also intermediaries) face to sharing their data in a way that generates public value (food safety and public health in our case) and 2) how can these actors be incentivized to share their data and contribute to the building of a food traceability system? The remainder of this paper is organized as follows: section 2 presents the literature on public value, collaboration, and data sharing; section 3 explains the data and methods used in our study; section 4 describes and analyzes a case study in food traceability; and finally, in section 5 we present the theoretical and practical implications of our findings and suggest ideas for future research about this topic.

\section{Literature Review}

The literature has only recently started to address data sharing among different types of organizations and the generation of public value, with different perspectives still under development. In this section, we start with some evolving concepts we want to

\footnotetext{
${ }^{2}$ This is precisely one of the characteristics that sets up the difference between private value (the value or benefit that comes directly to the participants of a service or program) and public value
}

emphasize: public value, collaboration, and data sharing. We follow with two different, yet complementary approaches that bring these three concepts together: 1) smart disclosure and 2) data collaboratives. Finally, we introduce an overview of the food traceability literature, oriented to make the context of our specific case study clearer to the reader.

\subsection{Public Value, Collaboration, and Data Sharing}

The stimulus for the current debate about public value within the field of public management was Mark Moore's seminal book Creating Public Value: Strategic Management in Government [42]. In his book, Moore [42] suggested that public value could be conceptualized both in terms of the satisfaction of individuals who enjoy desirable outcomes and in terms of the satisfaction of citizens who have seen a collective need, fashioned a public response to that need, and thereby participated in the construction of a community. Since this very first definition, practitioners and scholars have been searching for ways to operationalize and improve public value, moving beyond the fields of public administration and strategic management where it originated [43].

As a result, many definitions and characterizations for public value have developed over time. Bennington [44], for example, states that public value can be defined in two ways: what the public values and what adds value to the public sphere. Bovaird and Loeffler [45] suggest that public value has different dimensions (user value, value to wider groups, social value, environmental value, and political value) and Zhang, Puron-Cid, and Gil-Garcia [5] explain public value as the accumulation of long-term benefits that go beyond individual selfinterests, such as national security, fairness, equality, and environmental sustainability ${ }^{2}$.

More recently, Page, Stone, Bryson, and Crosby [6], Prebble [46], and Crosby, Hart, and Torfing [47] have discussed the connection between collaboration and the creation of public value. In their work, Page, Stone, Bryson, and Crosby [6] state that the ultimate test of collaboration is how much public value it produces, that is, the extent to which "collaboration achieves its overarching and subsidiary purposes, meets applicable mandates, and achieves lasting and widespread benefits at reasonable cost that no single organization could have achieved alone in a democratically accountable way" ( $p$. 716). Collaboration is not always easy, however, because it usually involves different policy-making

(the value or benefit of a service or program to the community as a whole). 
processes and stakeholders, with different interests and expectations [6]. Previous studies show that collaboration happens when there are asymmetric resources at stake as well as incentives for stakeholders to participate [8]. Thus, sharing information and data becomes critical in collaborative processes, and may contribute to building and supporting trust.

Gil-Garcia, Pardo, and Burke [9] state that information and data sharing is a complex multidimensional phenomenon with four interrelated component parts: 1) trusted social networks (networks of social actors who know each other and trust each other), 2) shared information (sharing of tacit and explicit knowledge in the form of formal documents, informal talks, e-mail messages, faxes, etc.), 3) integrated data (integration of data at the level of data element standards and/or industry/community data standards), and 4) interoperable technical infrastructure (systems that can communicate with each other at the hardware/operating system level). This definition is not technical or social, but acknowledges the important intersection between these two aspects, while simultaneously recognizing the key role of technology.

Our study further explores asymmetric information along the local product supply chain, the incentives local farms and institutional buyers have to share their data, and the role of technology in data sharing processes.

\subsection{Smart Disclosure}

One approach to addressing the topic of data sharing among different stakeholders to increase public value is smart disclosure. According to Sustein [3], smart disclosure can be defined as "timely release of complex information and data in standardized, machine readable formats in ways that enable consumers to make informed decisions". Seven principles characterize smart disclosure: accessibility and usability, standardization, machine readable formats, timeliness, interoperability, market adaption and innovation, and disclosure that fully protects consumer privacy [3].

Smart disclosure requires wider collaboration by providing information upon which choices can be made by the public, including businesses and citizens [4]. The Obama administration embraced the idea of smart disclosure early. In January 2009, the Office of Information and Regulatory Affairs (OIRA) issued a Memorandum on Disclosure and Simplification as Regulatory Tools aimed at providing guidance for the use of disclosure as a regulatory approach.

In addition to the general benefits of disclosing private data, Jarman and Luna-Reyes [2] list the specific benefits of smart disclosure for the different actors involved:
- Public agencies: to promote greater consumer access to information which can influence the goods and services that they purchase, to promote innovative use of data in ways that can increase profitable economic activity, and to reduce regulatory burdens and costs through greater data transparency and public-private collaboration.

- Private organizations: opportunities for market differentiation (by showing, for example, that their product is fresher, healthier, or more local), to build brand identification and commercialization opportunities.

Yet, and despite the potential of technology to promote smart disclosure, there are certain barriers that need to be overcome to make product data public. Sayogo and Pardo [4] differentiate between three types of determinants: 1) technological factors (interoperability and social media advancement), 2) economic factors (cost of disclosure and market structure and competitiveness), and 3) internal factors (strategic fit and alignment and reputation risk). In their work, Jarman and Luna-Reyes [2] also find similar barriers. In particular, the authors refer to the cost of disclosure, competition and commercial sensitivity, legal challenges, data quality, interoperability, and the access versus privacy dilemma.

\subsection{Data Collaboratives}

The second approach we want to present is that of data collaboratives. This perspective has been developed only very recently by Susha, Jannsen, and Verhulst [1] [10]. According to Verhulst, Youn, and Srinivasan [11], data collaboratives are a new form of collaboration, beyond the public-private partnership model, in which participants from different sectors (including private companies, research institutions, and government agencies) can exchange data to help solve public problems. As Susha, Jannsen, and Verhulst [1] put it, in this definition an essential element is that organizations from different sectors collaborate together to create value from data.

The five ways that data collaboratives create public value are [11]: 1) situational awareness and response, 2) public service design and delivery, 3) knowledge creation and transfer, 4) prediction and forecasting, and 5) impact assessment and evaluation.

The field of data collaboratives is still at its infancy. Most of the available research has been conducted by Susha and colleagues under the umbrella of the Data Collaboratives initiative promoted by the Gov Lab (see http://datacollaboratives.org/). Susha, Jannsen, and Verhulst [1][10] have mainly worked to depict a taxonomy of forms of data collaboratives and to analyze 
the coordination problems and coordination mechanisms associated with data collaboratives. The taxonomy the authors develop [1] consists of six dimensions related to data sharing (type of data, content of data, administrative level associated with data, diversity of data providers, facilitation, and degree of access to data) and eight dimensions related to data use (target user group of data, user selection, research or policy problem, incentive for data use, continuity of collaboration, outcome of data collaborative, collaboration among data users, purpose of use). In addition, in their second work [10], the authors use this taxonomy to discuss how different forms of data collaboratives may require different coordination mechanisms.

Further, the authors argue that data collaboratives present an example of the bazaar form of coordination. At the task level, the authors identify five coordination problems: 1) matching potential data providers and data users, 2) maintaining control over the data and their unforeseen use once shared, 3) matching a particular research/policy problem with the specific attributes of the data required, 4) making sure the data shared by the data provider are useful and usable by the target user, and 5) aligning incentives for data providers to share proprietary data with the goals of data users. Finally, they discuss potential coordination mechanisms to address these problems, such as coordination by negotiation or mutual adjustment, by third party, and by standardization of norms, just to name a few examples.

\subsection{Food Traceability}

We understand traceability as the collection, documentation, maintenance, and application of information related to a product at every data point along the supply chain [17]. Traceability systems may provide a number of societal benefits (or public value), such as improved food safety, economic growth, and public health. One of the key factors in mitigating foodborne illness outbreaks is the ability to quickly detect the cause, origin, and spread of the incident. This is precisely where traceability, food safety, and public health are linked [48]. What's more, the capability for full trace-back and trace-forward at any stage in the food chain is generally considered critical to addressing declining consumer confidence and general public concerns about the rising incidence of food-related deaths and illnesses, which have been major public health issues in the developed countries [49].

The relevance of traceability systems to food safety and public health also shows the importance of the role of governments in supporting such systems. Governments' response can take place by means of laws and regulations, standards, policies (e.g., policies aimed at ensuring that foods are quickly removed from the system), and effective food safety monitoring and quality control systems [50] [22].

The literature on traceability has mainly taken the industry's perspective into account. For example, Alfaro and Sebrek [12] studied traceability as a management tool to improve performance. However, large food corporations are not the only players in this field. There are also small players, such as small farms, local restaurants, and convenience stores, which take up a large portion of the market, especially in the demand for local food. Yet these actors are often absent from whole chain systems and government policies only occasionally consider their needs and concerns [13].

Interestingly enough, one of the major challenges to creating global traceability for food produced by small farms is the burden placed on those farms in terms of providing data at that first point in the supply chain [18]. Farms often give precedence to activities that are more pressing than recording data; or they are ignorant of the importance of collecting, recording, and sharing data. Additionally, they may lack capabilities (skills, time, resources, etc.) to conduct such activities [18][25][20][21].

Small farms represent only part of the whole-chain traceability challenge. Traceability requires an understanding of the needs and expectations of both the farms and their customers. Jamar and Luna-Reyes [2] show that institutions often lack the motivation to support transparency due to concerns about commercial privacy and information disclosure.

Building traceability systems also requires institutions to adjust their business processes, such as engaging with multiple suppliers due to the possibility that small farms cannot ensure consistent fulfilment of product quota [26]. In fear of liability from food contamination, many institutions require the suppliers to carry food safety and product liability insurance [27]. Institutions are also challenged by the risks to their information and data management when investing in traceability. They must be prudent in reviewing and expanding their data-sharing protocols to ensure the security of their own data and systems. Furthermore, the institutions must be able to identify critical data elements from the traceability efforts to enable them to choose which data elements are the most beneficial for achieving the institution's goals.

Despite the relevance of the contribution of food traceability systems to increasing public value, there is still a limited body of literature addressing this issue. Thus, a better understanding of the critical factors affecting small farms and institutions in their efforts to build effective food traceability systems is still necessary, particularly related to the role of shared information and data. Our study aims to shed some light 
on the obstacles and incentives to local farms and institutions in building a whole-chain food traceability system.

\section{Research Design and Methods}

The most appropriate way to address descriptive or explanatory research questions is through a qualitative case study [14]. Qualitative case studies are well suited to respond to "how" and "what" questions and allow us to study the research question in depth while leaving room for unexpected and interesting findings that can form the basis for concrete hypotheses to be tested in future research [15]. In order to unpack how different actors can be incentivized to share their data in a way that promotes the public value of the information disclosed, we conducted a case study in New York State, funded by the National Science Foundation and aimed at understanding how different actors, and particularly small farms, could be incentivized to contribute to the building of a food traceability system. We were specifically interested in understanding the role of data and technology for food traceability. Our research addressed the lack of understanding of the social and technical barriers small farms and institutional buyers face in their interactions as part of a traceability system. We argue that data and technology architectures are needed to lower the barrier to entry for small farms.

We conducted two rounds of interviews. During the first round, nine semi-structured interviews were conducted with farm owners (five), institutional representatives (two), and New York State government officials (two), using different interview protocols for each type of stakeholder. Farm owners were identified by one of the project team members, who is a farmer himself. Additional interviewees were identified using the method of referral sampling. We asked the first interviewees to refer us to other colleagues involved or interested in food traceability, who then referred us to a colleague, and so on. We stopped once referrals became repetitive. The interviews focused on the definition of local, benefits and challenges of farms selling to institutions, benefits and challenges of institutions buying from local farms, data collection processes, involvement in traceability processes, and the role of technology. Interviews had an average duration of 6090 minutes.

During the second round, we conducted six additional interviews: three with non-profits involved in the topic of food safety and food traceability and three more with intermediaries. This second round was actually the result of our first conversations, which showed that there are more actors interested and involved in food traceability than the ones that we previously considered. Referral sampling was also used in this second round of interviews. We developed new protocols, although the topics remained the same. The duration of these interviews was about 60 minutes.

All interviews were recorded and transcribed. To increase data reliability, the interviewers made or reviewed and revised all transcriptions. The interviews were analyzed using codes derived from the existing literature on information sharing, collaboration, and private data use for public value, smart disclosure, data collaboratives, and food traceability. Table 1 shows some of the specific categories that were used as well as examples of each of such categories.

Table 1. Examples of categories used in the analysis of interviews

\begin{tabular}{|c|c|}
\hline Category & Illustrating quotes \\
\hline Local & $\begin{array}{l}\text { "Local, I will probably say one and } \\
\text { half to two hours I guess radius. It } \\
\text { is } 120-150 \text { miles probably" } \\
\text { "Local as grown and produced } \\
\text { within } 250 \text { miles. So we follow that } \\
250 \text { miles" }\end{array}$ \\
\hline Trust & $\begin{array}{l}\text { "Certainly, there will be a lot of } \\
\text { trust. I mean that is where knowing } \\
\text { the local, like there is a few guys in } \\
\text { the (deleted) area that do mess } \\
\text { around. See a lot of (deleted) } \\
\text { cabbage coming out and get a } \\
\text { different label put on it saying it is } \\
\text { local" } \\
\text { "So because we have those } \\
\text { relationships that you build up and } \\
\text { you kind of just trust... you have to } \\
\text { trust, cause you won't be able to } \\
\text { go and visit all the farms they're } \\
\text { gonna use" }\end{array}$ \\
\hline Food safety & $\begin{array}{l}\text { "And I remember the general } \\
\text { manager at (deleted) said yeah, } \\
\text { they must track the stuff because } \\
\text { from food safety perspective, if } \\
\text { someone is sick, we need to know } \\
\text { where it came from" } \\
\text { "But the consumers were a little } \\
\text { more sophisticated and they want } \\
\text { to understand something about } \\
\text { transparency, traceability, and } \\
\text { food safety, who are you, and } \\
\text { maybe environment stewardship, } \\
\text { which is why we are doing } \\
\text { something specifically about that } \\
\text { in (deleted)" }\end{array}$ \\
\hline Cost & $\begin{array}{l}\text { "Yeah. If it didn't add a lot of labor } \\
\text { or cost for farm to adopt } \\
\text { technology to support better } \\
\text { traceability. But they don't have } \\
\text { the incentive to do that since their } \\
\text { market don't require that" }\end{array}$ \\
\hline Technology & $\begin{array}{l}\text { "Lots of people have talked about } \\
\text { in that time the barriers to }\end{array}$ \\
\hline
\end{tabular}




\begin{tabular}{|l|l|}
\hline connecting people along local and \\
regional food value chain and they \\
have tried to intervene that \\
challenge through technology. For \\
example, (deleted) coming out of \\
(deleted), was started by a guy \\
named (deleted) and he tried to \\
intervene in this distribution \\
challenge through an online \\
platform" \\
"So I think that bar-coding \\
technology will be great and it may \\
involve more infrastructure at farm \\
level. Where you have farms do it, \\
you would have distributors do it"
\end{tabular}

\section{Analysis and Results}

In this section, we organize our findings around the challenges of participating in a food traceability system for both farms and institutions and attempt to highlight some of the issues as they relate to the main concepts identified in the literature review.

Our interviews showed that challenges for farmers and institutions were intertwined. Some of the issues reported by the interviewees were clearly related to small farms, whereas other issues were clearly associated with institutions. Yet, there were a set of factors that applied to both small farms and institutions.

The following were the main challenges in relation to farms:

- Guaranteeing a sustainable supply: Agriculture is a volatile market. Farmers strongly depend on the weather and on climatic phenomena, such as droughts. If a product's supply is not guaranteed, institutions might buy from different farmers. In addition, local farms do not offer a substantial variety of produce. Thus, volatility results in institutions' lack of loyalty and, in turn, jeopardizes local farms' profitability in the long run.

- Regulations: Farms need to comply with several regulations. As one of our interviewees said, "The state is requiring certifications but getting certifications is a challenge for local farmers". Institutions also referred to the importance of requesting certifications from farmers, recognizing how difficult this process could be for small farms. In addition, there are food safety requirements (such as inspections) that farmers need to comply with.

- Lack of market skills: Some of our interviewees stated that farmers are more accustomed to selling in farmers' markets where social and personal connections and relationships are very important. Selling to institutions completely changes the context and requires the adoption of more formalized procedures regarding, for example, purchasing, delivery, and payment. However, usually, small farmers lack the necessary skills and capabilities to participate and take full advantage of this new selling-buying process.

However, our interviewees consistently agreed that a poor data collection process was the most important barrier. According to them, local farms usually keep records on costs and sales. They are also required to have a food safety plan so they also collect data about that. Local farms that want to differentiate themselves, for example, by being organic, collect additional types of data, such as data on fertilizers and pests. Our interviewees from institutions and governmental organizations, however, believed that farms need to collect more data. One government representative said, "We really want farmers to succeed in this market so they really need to collect these data. They need to see what works and to be closer to the buyers' perspective".

Most farmers do not use computers or technological tools to collect data. According to one of our interviewees, small farms lack technological skills. Learning, understanding, and actually using the technological tools is a major constraint. Farmers' age plays an important role as well: "If the farm is very small, this becomes the responsibility of one person in the farm (usually, one young person). If there are no young people in the farm, the process becomes more difficult”.

This finding aligns with findings from the literature. The gap between the data collection requirements and 
the data and technology capabilities of small farms has already been reported by, among others, Sayogo, Zhang, Luna-Reyes, Jarman, Tayi, and Andersen [18]; Tran, Bailey, Wilson, and Phillips [20]; Kleppel [21]; and Parikh, Patel, and Schwartzman [25]. Further, in terms of Sayogo and Pardo [4], the weakness of the data collection processes could be considered a technological factor (lack of technology to collect the data), an economic factor (not only the economic cost of investing in the necessary technology and actually collecting the data, but also the opportunity cost of "getting people to change from what they are doing now, $[\ldots]$ to something else", as one of our interviewees told us), and an internal factor (the lack of skills, but also not being aware or misunderstanding the strategic opportunity of collecting the data).

Interviewees also referred to barriers from the institutions' perspective. The first one had to do with the confirmation of localness. They explained that it is difficult for institutions to guarantee the products they are buying are local. Usually, transactions take place through intermediaries, who are the ones who can confirm the local attribute of a certain product. Interestingly enough, these intermediaries do not tend to provide additional information to show localness. Thus, institutions' trust in intermediaries plays a major role in this respect.

Proving localness is so important to institutions that discussing what "local" means to them deserves further attention. The literature has actually discussed the nature of localness for years, linking it to some of these attributes: energy [28], farm size and practice issues [21][29][30][31], freshness and nutrition [32][33][34], and other factors (e.g., social movements, see Ploeg [35]). Yet, institutions' definition of local was mainly about distance. One of our interviewees declared: "local is mainly about distance: produced within a 100-mile radius". Yet, this definition was somewhat flexible for other interviewees who accepted any food grown in New York State as local: "NYS grown and produced product is local. So I'd rather say that our definition has to do with both distance and production". The literature has also referred to distance as a way to define local. However, the selection of a distance standard has been largely arbitrary. Smith and McKinnon [36] use a 100mile local radius, but Peters et al. [37] use a $50 \mathrm{~km}(30$ mile) radius as the distance criterion for local production.

Governments' definition of local is quite aligned with institutions'. Our interviewees referred to the vagueness of the term, but still preferred to link it to miles (distance) or to being produced in New York State

\footnotetext{
${ }^{3}$ Interestingly enough, for farms, local had to do with several
} characteristics of the product (such as freshness and nutritional (and therefore making a contribution to supporting the local economy or influencing the diet of the people they serve $)^{3}$.

In addition to confirmation of localness, our interviewees also referred to administrative burdens. According to one of them, "There is heavy work in purchasing from a small farm. It is easier to get one or two big vendors [...]. Buying from local farms can be very expensive". Another one said, "Most of the institutions are not going to buy from very small farms. And that is basically because they need information but, overall, they need more supply from these small farms and these small farms cannot offer a big production". Thus, economic factors matter, as Sayogo and Pardo [4] and Harris, Lott, Lakins, Bowden, and Kimmons [26] have previously shown.

Finally, and as in the case of farms, our interviewees mentioned the deficiencies in the data collection process. The data and information requested by institutions is mainly collected by intermediaries. They basically use pen and paper. And the data they do collect is limited because they do not feel it is necessary to gather additional information. They believe the purchasing process is more about knowing the people and the industry. Due to deficiencies in the data collection process, tracing food back to confirm that it comes from a small, local farm is very difficult. As previously indicated, most of our interviewees said traceability is about trust between the farm and the intermediary and between the intermediary and the institutions, in accordance with prior work (Gil-Garcia, Pardo, and Burke [9] and Susha, Jannsen, and Verhulst [1] [10]). Still, the interviewees recognized the potential of having a direct link between farms and institutions, which could be facilitated by technology. According to one of the individuals we talked to, "The technology is available but we are not using it".

There is no doubt that technology can play a more prominent role in the data collection and traceability processes. For many of our interviewees, the future of traceability systems will be shaped by technology. One of our interviewees stated, "If you want to be accountable, you need to use technology because it is an easy way to store data and track it. It is the easiest, particularly, with mobile devices".

Although several technological tools, such as bar coding, are already available, two main barriers regarding the use of these tools emerged in the interviews. First, interviewees mentioned the challenge of actually using such tools, particularly if their adoption requires changes in the way the purchasing process has been handled previously (particularly by

issues) and the farm (such as sustainability, farm size, and practice issues). 
distributors/intermediaries). Second, having a cyberinfrastructure architecture for food traceability that linked small farmers directly with institutions could result in questions about the need for intermediaries, increasing their resistance to being part of the change.

As these findings indicate, the costs of participating in the purchasing process are high for both small farms and institutions. The lack of communication and trust between the different parties further hinders the process, particularly when interactions between these two parties are indirect and take place by means of distributors and intermediaries.

\section{Concluding Remarks}

Our findings show that there are several barriers that need to be overcome for whole-chain food traceability and which play an important role in incentivizing different types of actors to disclose and share their data. Among the challenges presented, our research shows that the difficulties experienced by both local farms and institutional buyers during the data collection process are key in impeding the promotion of a food traceability system based on the sharing of data and technological tools. In accordance with the literature, technological, economic, and internal factors are important constraints for both types of actors [4].

As a result, we argue that there are several actions that may contribute to incentivizing small farms and institutions to participate in this type of data sharing. On one hand, we believe that showing the benefits of having a whole-chain food traceability system to both small farms and institutional buyers is key. Such a system would 1) enable quicker identification of the sources of food borne illness, contributing to food safety and public health, 2) enable more small farms to sell their products to mainstream markets through wholesalers and allow retailers to add those farms to their chain-of-custody, thereby tracking products from source to customer and benefiting from premium market prices supported by "locally grown" products, and 3) provide more and better data to support the development of improved food safety policies. Yet, farms and institutions need to realize that these benefits will pay off, particularly in relationship to the initial efforts and costs they need to incur.

In addition, small farms likely need to participate in training activities that cover a wide range of issues, from purchasing processes to data collection and use of technology. Institutions also need to be part of training activities on the use of software and technical tools to help trace products back to their origins. In addition, institutions need information about how to purchase with integrity and how to document their purchases (for example, how much money has been spent on buying food). Governments may contribute to support these efforts, for example, by providing a platform for data disclosure [18] or by maintaining some level of data quality that could contribute to overcoming the cost of disclosure [2][38]. The role of governments needs to be further explored given the relevance of traceability systems to food safety and public health. Further research is therefore needed on specific policies, laws and regulations, required standards, and effective food safety monitoring and quality control systems, among others, that show how public organizations can contribute to improving food traceability and, as a result, to increasing public value.

Our findings reveal additional new topics that are worth exploring. We believe several academic fields would benefit from a more general study of the contribution of food traceability to both private and public value, which would also result in a more in-depth discussion of the differences between these two concepts. Exploring the actual ties among different types of actors would also be of interest. Research on the social networks among farmers, government officials, and institutional buyers, for example, could provide additional information on trust and its impact on data-sharing processes. Finally, and given the importance of data collection processes, further research could also consider in-depth study of data management practices, not only among local farms, but also across intermediaries and institutional buyers.

\section{References}

[1] Susha, I., Jannsen, M. and Verhulst, S. "Data Collaboratives as a New Frontier of Cross-Sector Partnerships in the Age of Open Data: taxonomy Development". Proceedings of the $50^{\text {th }}$ Hawaii International Conference on System Science, IEEE Computer Society, Big Island, HI, January $4^{\text {th }}-7^{\text {th }}, 2017$ a, pp. 2691-2700.

[2] Jarman, H. and Luis. F.L. Private Data and Public Value: Governance, Green Consumption, and Sustainable Supply Chains, Springer, Switzerland, 2016.

[3] Sustein, C. "Informing Consumers through Smart Disclosure". Retrieved from https://obamawhitehouse.archives.gov/blog/2012/03/30/infor ming-consumers-through-smart-disclosure, March 30 ${ }^{\text {th }}, 2012$.

[4] Sayogo, D. S. and Pardo, T. A. "Understanding Smart data Disclosure Policy Success: The Case of Green Button". Proceedings of the $14^{\text {th }}$ Annual International Conference on Digital Government Research, ACM, June $17^{\text {th }}-20^{\text {th }}, 2013$, pp. $72-81$.

[5] Zhang, J., Puron-Cid, G., \& Gil-Garcia, J. R. (2015). "Creating public value through Open Government: Perspectives, experiences and applications." Information 
Polity: The International Journal of Government \& Democracy in the Information Age, 2015, 97-101.

[6] Page, S. B, Stone, M. M., Bryson, J. M. \& Crosby, B. C. "Public value creation by cross-sector collaborations: A framework and challenges of assessment", Public Administration, 93(3), 2015, pp. 715-732.

[7] Osborne, S. "The New Public Governance?", Public Management Review, 8(3), pp. 377-387.

[8] Ansell, C. and Gash, A. "Collaborative governance in theory and practice". Journal of Public Administration Research and Theory, Oxford University Press, Oxford, United Kingdom, 2008, pp. 543-571.

[9] Gil-Garcia, J. R., Pardo, T. and Burke, B.. "Conceptualizing information integration in government". In H. J. Scholl (ed.), E-government. Information, technology and, transformation, M. E. Sharpe, Amonk, NY, 2010, pp. 179-202.

[10] Susha I., Janssen M. and Verhulst S. "Data collaboratives as 'bazaars'?: A review of coordination problems and mechanisms to match demand for data with supply" Transforming Government: People, Process and Policy, Emerald Publishing Limited, Bingley, United Kingdom, 2007, pp. 157-172.

[11] Verhulst, S., Young, A. and Srinivasan, P. An Introduction to Data Collaboratives. Creating Public Value by Exchanging Data. The GovLab, UNICEF, Omidyar Network, New York, 2017.

[12] Alfaro J. \& Sebrek S. S. “Traceability management as a multidisciplinary topic: Trends and gaps in recent scholarly research" School of Economics and Business Administration, University of Navarra in its series Faculty Working Papers, 2015.

[13] Bhatt, T., Buckley, G., \& McEntire, J. "Proceedings of the August 2011 Traceability Research Summit". Journal Of Food Science, 2013, pp. Suppl 2B9-B14.

[14] Marshall, C., \& Rossman, G. B. Designing qualitative research. Sage Publications, Thousands Oaks, California: 2011.

[15] Yin, R. K. Case study research: design and methods, SAGE, Los Angeles, 2014.

[16] Taylor, D. A. "Does One Size Fit All?: Small Farms and U.S. Meat Regulations". Environmental Health Perspectives, 2008, pp. A529-A531.

[17] Opara, L. U. "Traceability in agriculture and food supply chain: a review of basic concepts, technological implications, and future prospects". Journal of Food, Agriculture and Environment, 2003, pp. 101-106.

[18] Sayogo, D., Zhang, J., Luna-Reyes, L., Jarman, H., Tayi, G., Andersen, D., \& Andersen, D. "Challenges and requirements for developing data architecture supporting integration of sustainable supply chains". Information Technology \& Management, 2015, pp. 5-18.

[19] Hoppe, R. A. Structure and Finances of U. S. Farms: Family Farm Report (2014 Ed.). DIANE Publishing, 2014.

[20] Tran, N., Bailey, C., Wilson, N., and Phillips, M. "Governance of Global Value Chains in Response to Food Safety and Certification Standards: The Case of Shrimp from Vietnam". World Development, 2013, pp. 45, 325-336.

[21] Kleppel, G. 2014. The Emergent Agriculture. New Society, Gabriola Island, BC

[22] Drew, C. A., \& Clydesdale, F. M. "New Food Safety Law: Effectiveness on the Ground". Critical Reviews in Food Science and Nutrition, 2015, pp. 689-700.

[23] Golan, E., Krissoff, B., Kuchler, F., Calvin, L., Nelson, K., \& Price, G. Traceability in the U.S. Food Supply: Economic Theory and Industry Studies (Agricultural Economic Report No. 830). Economic Research Service, Washington DC, 2004.

[24] Olsen, P., \& Borit, M. "How to define traceability". Trends in Food Science \& Technology, 2013. pp. 142-150.

[25] Parikh, T. S., Patel, N., \& Schwartzman, Y. "A survey of information systems reaching small producers in global agricultural value chains". International Conference on Information and Communication Technologies and Development, 2007, pp. 1-11.

[26] Harris, D., Lott, M., Lakins, V., Bowden, B., \& Kimmons, J. "Farm to institution: creating access to healthy local and regional foods". Advances in Nutrition, 2012, pp. 343-349.

[27] Markley, K., Kalb, M., \& Gustafson, L. Food Safety and Liability Insurance: Emerging Issues for Farmers and Institutions (A Community Food Security Coalition Report), Center for Integrated Agricultural Systems, Wisconsin, 2010.

[28] Pirog, R., T. VanPelt, K. Enshayan and E. Cook, Food, fuel, and freeways: An Iowa perspective on how far food travels, fuel usage, and greenhouse gas emissions. Iowa State University, Ames, 2001.

[29] Pollan, M., The Omnivore's Dilemma. Penguin, New York, 2006

[30] Ikerd, J., Small Farms are Real Farms. Acres USA, Austin, 2008.

[31] Ackerman-Liest, P., Rebuilding the Foodshed. Chelsea Green, White River Junction, Vermont, 2014.

[32] Asami, D.K., Y.-J. Hong, D.M. Barrett and A.E. Mitchell. "Comparison of the total phenolic and ascorbic acid content of freeze-dried and air-dried marionberry, strawberry, and corn 
grown using conventional, organic, and sustainable agricultural practices". Journal of Agricultural and Food Chemistry, 2003, pp. 1237-1241.

[33] Vallejo, F., F. Tomaas-Barberaan and C. GarciaaViguera, "Health-promoting compounds in broccoli as Influenced by refrigerated transport and retail sale period". Journal of Agricultural Food and Chemistry 2003, pp. 30293024.

[34] Rickman, J.C., D.M. Barrett and C.M. Bruhn, "Nutritional comparison of fresh, frozen and canned fruits and vegetables. Part 1. Vitamins $\mathrm{C}$ and $\mathrm{B}$ and phenolic compounds". Journal of the Science of Food and Agriculture, 2007, pp. 930-944.

[35] Ploeg, J. vander. The New Peasantries. Taylor Francis, New York, 2009

[36] Smith and J.B. McKinnon. The 100-Mile Diet. Random House, New York, 2007.

[37] Peters, C.J., Bills, N.L, Lembo, A.J., Wilkins, J.L., and Fick, G.W., Mapping potential, foodsheds in New York State: A spatial model for evaluating the capacity to localize food production. Renewable Agriculture and Food Systems, 2009, pp. $72-84$.

[38] Ran, W., Jarman, H., Luna-Reyes, L. F., Zhang, J., Andersen, D., Tayi, G., \& Andersen, D. "Supply-Chain Transparency and Governance Systems: Market Penetration of the I-Choose System. Information”, Models \& Sustainability, 2016, pp. 67-92.

[39] Rainey, H. G. \& Bozeman, B. "Comparing public and private organizations: Empirical research and the power of the a priori", Journal of Public Administration Research and Theory, 2000, pp. 447-469.

[40] Perry, J. L. \& Rainey, H. G. "The public-private distinction in organization theory: A critique and research strategy", Academy of Management Review, 1988, pp. 182201.

\section{Acknowledgements}

This paper presents results from the research project "Towards a Data and Technology Architecture for Smart Food Policy: Understanding the Critical Factors of Food Traceability for Small Farms", funded by the National Science Foundation under grant no. 1649820. The authors want to thank the valuable contributions of all the members in the research team, particularly of the co-PI Dr. Gary Kleppel. All the errors or omissions are the sole responsibility of the authors. The results do not necessarily represent the official views of NSF.
[41] Wamsley, G. L. \& Zald, M. N. The political economy of public organizations, Lexington. Lexington, MA, 1973.

[42] Moore, M. H. Creating public value: Strategic management in government, Harvard University Press, Cambridge, MA, 1995.

[43] Bennington, J. \& Moore, M. H. Public value: Theory and practice, Palgrave Macmillan, London, 2011.

[44]. Bennington, J. "From private choice to public value?" In Bennington, J. \& Moore, M. H. (eds). Public value: Theory and practice, Palgrave Macmillan, London, 2011, pp. 31-51.

[45] Bovaird, T. \& Loeffler, E. "From engagement to coproduction: The contribution of users and communities to outcomes and public value". VOLUNTAS: International Journal of Voluntary and Nonprofit Organizations, 2012, pp. 1119-1138.

[46] Prebble, M. "Public value and limits to collaboration", International Journal of Public Administration, 38(7), 2015, pp. $473-485$

[47] Crosby, B. C., Hart, P. \& Torfing, J. "Public value creation through collaborative innovation", Public Management Review, 19(5), 2017, pp. 655-669.

[48] Souza-Montei. ro, D. M. \& Hooker, N. H. "Food safety and traceability". In Armsbruster, W. \& Knutson, R. D. (eds.) US Programs Affecting Food and Agricultural Marketing, Springer, New York, 2013, pp. 249-271.

[49] Opara, L. U. "Traceability in agriculture and food supply chain: A review of basic concepts, technological implications, and future prospects", Food, Agriculture and Environment, 1(1), 2003, pp. 101-106.

[50] Duan, Y., Miao, M., Wang, R., Fu, Z. \& Xu, M. “A framework for the successful implementation of food traceability systems in China", The Information Society: An International Journal, 33(4), 2017, pp. 226-242. 